\title{
Article \\ Utilizing the DNA Aptamer to Determine Lethal $\alpha$-Amanitin in Mushroom Samples and Urine by Magnetic Bead-ELISA (MELISA)
}

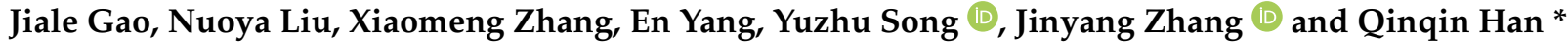

check for

Citation: Gao, J.; Liu, N.; Zhang, X.; Yang, E.; Song, Y.; Zhang, J.; Han, Q Utilizing the DNA Aptamer to Determine Lethal $\alpha$-Amanitin in Mushroom Samples and Urine by Magnetic Bead-ELISA (MELISA). Molecules 2022, 27, 538. https:// doi.org/10.3390/molecules27020538

Academic Editors: Wojciech

Kolanowski and Anna

Gramza-Michałowska

Received: 31 December 2021

Accepted: 12 January 2022

Published: 15 January 2022

Publisher's Note: MDPI stays neutral with regard to jurisdictional claims in published maps and institutional affiliations.

Copyright: (C) 2022 by the authors. Licensee MDPI, Basel, Switzerland. This article is an open access article distributed under the terms and conditions of the Creative Commons Attribution (CC BY) license (https:// creativecommons.org/licenses/by/ $4.0 /)$.
Faculty of Life Science and Technology, Kunming University of Science and Technology, Kunming 650500, China; jialegaoj1@163.com (J.G.); Iny15387658750@163.com (N.L.); Z1303167982@163.com (X.Z.); yangen@kust.edu.cn (E.Y.); syzzam@126.com (Y.S.); zhangjinyangzjy@163.com (J.Z.)

* Correspondence: hanqq@kust.edu.cn; Tel.: +86-(0871)-65939528

\begin{abstract}
Amanita poisoning is one of the most deadly types of mushroom poisoning. $\alpha$-Amanitin is the main lethal toxin in amanita, and the human-lethal dose is about $0.1 \mathrm{mg} / \mathrm{kg}$. Most of the commonly used detection techniques for $\alpha$-amanitin require expensive instruments. In this study, the $\alpha$-amanitin aptamer was selected as the research object, and the stem-loop structure of the original aptamer was not damaged by truncating the redundant bases, in order to improve the affinity and specificity of the aptamer. The specificity and affinity of the truncated aptamers were determined using isothermal titration calorimetry (ITC) and gold nanoparticles (AuNPs), and the affinity and specificity of the aptamers decreased after truncation. Therefore, the original aptamer was selected to establish a simple and specific magnetic bead-based enzyme linked immunoassay (MELISA) method for $\alpha$-amanitin. The detection limit was $0.369 \mu \mathrm{g} / \mathrm{mL}$, while, in mushroom it was $0.372 \mu \mathrm{g} / \mathrm{mL}$ and in urine $0.337 \mu \mathrm{g} / \mathrm{mL}$. Recovery studies were performed by spiking urine and mushroom samples with $\alpha$-amanitin, and these confirmed the desirable accuracy and practical applicability of our method. The $\alpha$-amanitin and aptamer recognition sites and binding pockets were investigated in an in vitro molecular docking environment, and the main binding bases of both were T3, G4, C5, T6, T7, C67, and A68. This study truncated the $\alpha$-amanitin aptamer and proposes a method of detecting $\alpha$-amanitin.
\end{abstract}

Keywords: $\alpha$-amanitin; aptamer; truncated aptamers; MELISA; mushroom; urine

Key Contribution: We use the aptamer to establish a simple and specific magnetic bead-based enzyme linked immunoassay (MELISA) method for $\alpha$-amanitin. The detection limit was $0.1 \mu \mathrm{g} / \mathrm{mL}$; and this was used to detect $\alpha$-amanitin in mushroom samples and urine.

\section{Introduction}

Mushroom poisoning is a global problem, which poses a threat to human health. Mushroom poisoning occurs worldwide, due to accidental picking and consumption [1]. One study reported that $90 \%$ of deaths from mushroom poisoning were caused by mushrooms containing amatoxin [2]. $\alpha$-Amanitin is the most abundant lethal toxin among the amatoxins, with a lethal dose to humans of about $0.1 \mathrm{mg} / \mathrm{kg}$ [3]. When wild mushrooms containing amatoxin are accidentally consumed, the amatoxin enters the hepatocytes and binds to RNA polymerase II, which inhibits the transcription of mRNA and protein synthesis, eventually leading to necrosis of hepatocytes. In addition, amatoxin promotes the expression of apoptosis factor caspase-3, Annexin V, and the P53 protein, and decreases expression of the anti-apoptosis factor Bcl-2 protein, causing damage; however, the exact mechanism remains unclear [4-6]. No specific antidote has been found for amatoxin. It has been reported that polymyxin B competes for the RNA polymerase II binding site; thus, inhibiting the binding of $\alpha$-amanitin to RNA polymerase II. Animal experiments have shown that polymyxin B significantly reduces the liver and kidney injury induced by $\alpha$-amanitin in mice [7], but no further clinical trials have been reported. 
$\alpha$-Amanitin is a cyclic octapeptide. Cyclic peptides have a richer structural and functional diversity and better conformational and metabolic stability, due to their sequence diversity and loop structure, compared with linear polypeptides [8]. Owing to their specific structures, cyclic peptides have become a hot research topic in biology and pharmacology. According to toxicological studies, amatoxins disappear rapidly from the serum, but can be detected in the urine within 4 days after ingestion $[9,10]$. As urine samples are relatively easy to obtain and the duration of amatoxins in urine is longer than that in serum, urine seems to be an obvious sample matrix for rapid detection of amatoxins. In recent years, more assays have emerged to detect $\alpha$-amanitin. For example, instrumental analyses have a high specificity and sensitivity, but these methods require expensive instrumentation and complex sample pre-treatment [11-14]. Staak [15] was the first to use an enzyme-linked immunosorbent assay (ELISA) to detect amatoxin in urine. He [16] prepared a monoclonal antibody that specifically binds to amatoxin and established a method for detecting amatoxin in mushrooms using an indirect competitive immunoassay, which identified $\alpha$-amanitin, $\beta$-amanitin, and $\gamma$-amanitin, with detection limits of $4.55,4.9$, and $4.45 \mathrm{ng} / \mathrm{mL}$, respectively. Although ELISA is simple and highly sensitive, the method has the disadvantages of high cost and long cycle time to prepare the monoclonal antibodies (mAbs), which need further improvement. Investigators have further established the lateral flow immunoassay (LFIA) to overcome the drawbacks of ELISA. Bever $[17,18]$ applied prepared mAbs to immunoassay strips to detect amatoxin. That experiment showed that LFIA can detect amatoxin in mushroom samples and urine, and the entire assay can be completed in $10 \mathrm{~min}$, resulting in the detection of a large number of samples in a short time. However, $\mathrm{mAbs}$ have a long preparation cycle, making aptamers a better choice for detecting $\alpha$-amanitin.

Aptamers are single-stranded DNA or RNA molecules that fulfill particular functions by coiling and folding into specific tertiary structures in the absence of the complementary strand and are screened from random oligonucleotide libraries using systematic evolution of ligands by exponential enrichment (SELEX), for highly sensitive and target-specific binding of the aptamers [19]. Aptamers undergo conformational changes and three-dimensional (3D) folding through base complementary pairing and other molecular forces, forming relatively stable 3D structures, such as hairpins, stem-loops, and G-quartets, which are the basis for aptamer-target binding [20,21]. Aptamers are also known as chemical antibodies, because their target recognition pattern is very similar to that of antigens and antibodies. However, aptamers have many advantages over antibodies. For example, aptamers have a low molecular weight, high stability, are easy to modify, have a wide target recognition range, and lack immunogenicity [22]. Therefore, aptamers have become important research tools in the fields of analytical chemistry and biochemistry. A biosensor based on the polymerase chain reaction (PCR) and streptavidin as a dual fluorescence polarization (FP) amplifier has been used to detect chloramphenicol residues in food, with a linear detection range of 0.001-200 nM [23]. An aptamer labeled with a reporter group (fluorophore) was used for qualitative or quantitative analysis of a test target by detecting the change in the signal upon binding of the aptamer to the target. By labeling the $5^{\prime}$ end of the aptamer with carboxy fluorescein and the $3^{\prime}$ end with Black hole quencher 1, the established aptamer molecular beacon method could be used to rapidly detect Aflatoxin B1 (AFB1) in samples [24]. The researchers also used the Thioflavin T (ThT) substitution assay, in which the ThT molecule fluoresces when bound to G4-quadruplex DNA, and the change in signal can be measured. FenA2 interacts with ThT to produce a label-free detection mode with a $\mathrm{Kd}$ of $33.57 \mathrm{nM}(9.30 \mathrm{ppb})$, and the detection limit for Fenitrothion was $14 \mathrm{nM}(3.88 \mathrm{ppb})$ [25].

The initial length of an aptamer is usually 70-100 nt, and not all bases are involved in the binding of the aptamer to the target. The excess bases may form a large spatial block, which hinders the recognition and binding of the aptamer to the target and increases the cost of synthesis [26]. In addition, a primitive aptamer with a long oligonucleotide sequence binds its target analog via a primer region or additional fragment, leading to impaired specificity [27]. A shorter aptamer has better penetration ability and facilitates the design and synthesis of aptamer probes for practical applications. Truncating the 88-nt melamine aptamer to 34-nt 
results in comparable binding ability and greater specificity to the target [27]. The affinity increased significantly and the Kd value of the aptamer decreased from $174 \pm 27 \mathrm{pmol} / \mathrm{L}$ to $14 \pm 1 \mathrm{pmol} / \mathrm{L}$ after truncating the 77-nt electric eel acetylcholinesterase aptamer to 39-nt [28]. However, when the specific platelet-derived growth factor adaptor was truncated to 36-nt, the affinity of the sequence increased 150 times, and the effect on the corresponding fibroblasts was consistent with the original sequence [29]. In summary, it is necessary to optimize the sequence after the target aptamer is screened.

Isothermal titration calorimetry (ITC) is a method that can be used to directly measure the thermal changes of reactions between substances and to directly obtain the parameters of the intermolecular binding process [30,31]. Through an ITC experiment, the dissociation constants (affinity, $\mathrm{Kd}$ ), reaction heat $(\Delta \mathrm{H})$, and the number of binding sites (ratio of ligand to macromolecule, N) can be obtained easily and quickly. Gold nanoparticles (AuNPs) are a nanoscale material with a high extinction coefficient and diameters of 1-100 nm [32]. AuNPs dispersed in solution appear red. When the appropriate concentrations of salts $(\mathrm{NaCl})$, surfactants, or cationic polymers are added, the color of the AuNP solution gradually changes from red to purple or blue, due to the aggregation of AuNPs [33]. Negatively charged single-stranded DNA (ssDNA) aptamers retain the stability of the AuNPs even in highly saline solutions, and the color of the solution remains burgundy. However, in the presence of a target, the aptamer binds to the target, and the appropriate $\mathrm{NaCl}$ concentration causes polymerization of the AuNPs, and the color of the solution changes from red to purple-blue [34,35]. This combination of AuNPs and an aptamer can be used for colorimetric detection of a target and to identify the affinity and specificity of the aptamer and target. ELISA is now widely used in various laboratories due to its simple operation, lack of need for large instruments, and simple sample pre-treatment process [36]. The combination of ELISA technology and magnetic beads for target detection is an emerging strategy. Magnetic beads are composite materials consisting of small metal particles containing superparamagnetic properties. When a magnetic field is present, the beads adsorb the magnetic field and separate from their solution; they return to their dispersed state when the magnetic field disappears [37,38].

In this study, we propose a colorimetric biosensor based on AuNPs and isothermal titration calorimetry (ITC) to identify the affinity and specificity of aptamers. The principle is that, after specific binding of the inducer to the target, the AuNPs aggregate and change color from red to purple when they encounter the salt solution. We developed a magnetic bead-based enzyme linked immunoassay (MELISA) to detect $\alpha$-amanitin, and this represents the first use of aptamer for a $\alpha$-amanitin detection. In this study, the aptamer was selected to replace the traditional antibody, and the biotin-labeled aptamer was immobilized on streptavidin magnetic beads using the streptavidin-biotin reaction to obtain magnetic beads that specifically recognized $\alpha$-amanitin. The competition between the target, $\alpha$-amanitin, and the complementary chain of the aptamer was used for detection, and a sensitive and rapid $\alpha$-amanitin detection method was established (Figure 1).

A

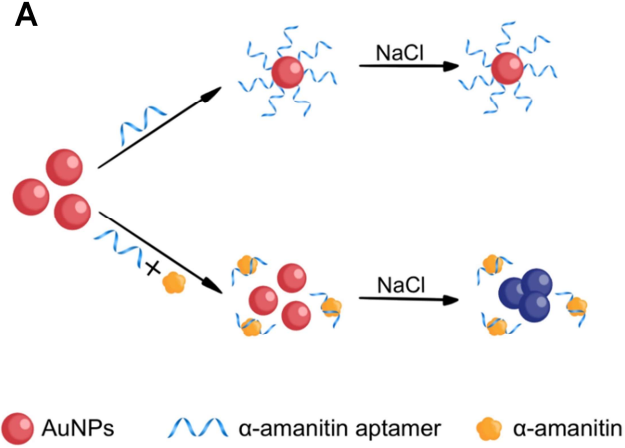

B

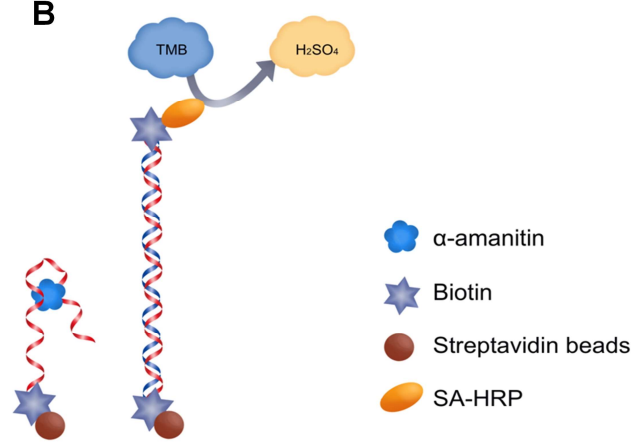

Figure 1. Experimental schematic. (A) Schematic illustration of the affinity of the $\alpha$-amanitin truncated aptamer by colloidal gold spectrophotometry. (B) Schematic illustration based on MELISA to detect $\alpha$-amanitin. 


\section{Results and Discussion}

\subsection{Truncation and Sequence Design of the Aptamers}

The stem-loop structure of the aptamer (also called the hairpin structure) is usually regarded as the site of recognition and binding to the target molecule. Therefore, as shown in Figure 2, the original sequence of the $\alpha$-amanitin aptamer fitted using Mfold had two stem-loop structures, and the redundant arms at both ends of the aptamer were truncated without destroying the original aptamer stem-loop structure. Twelve tailored and optimized aptamers were obtained, and five sequences with the optimal structure of each tailoring method were selected by secondary structural prediction, as shown in Table 1. Among these, Apt-2 is obtained by cutting through $5^{\prime}, \mathrm{Apt}-8$ is obtained by cutting through $3^{\prime}$ end, Apt-10 and Apt-11 are obtained by cutting through both $5^{\prime}$ and $3^{\prime}$ ends at the same time, and Apt-12 is obtained by cutting only one ring at both ends.

A

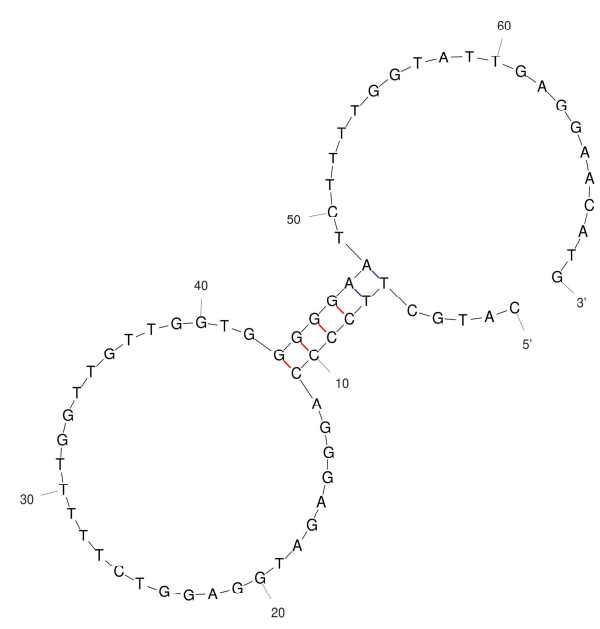

B

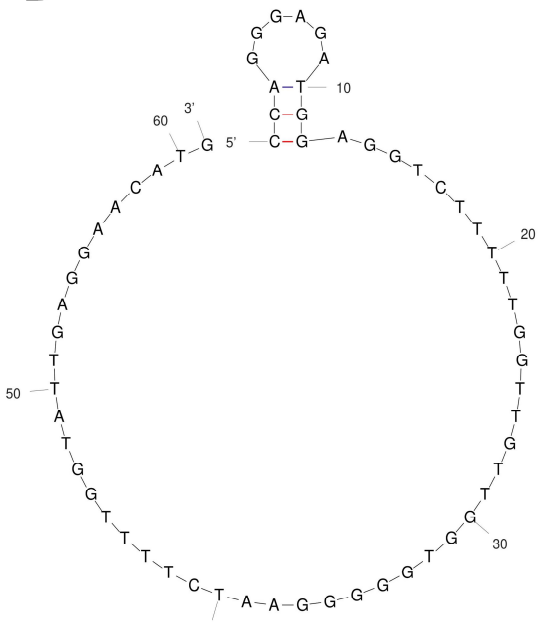

E

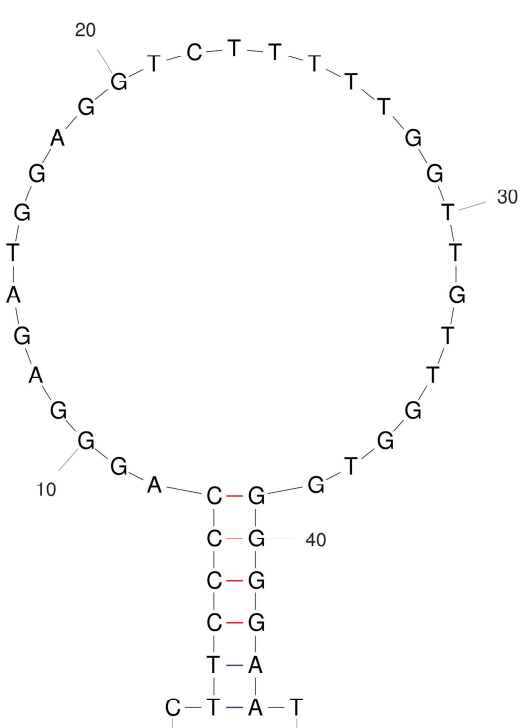

C

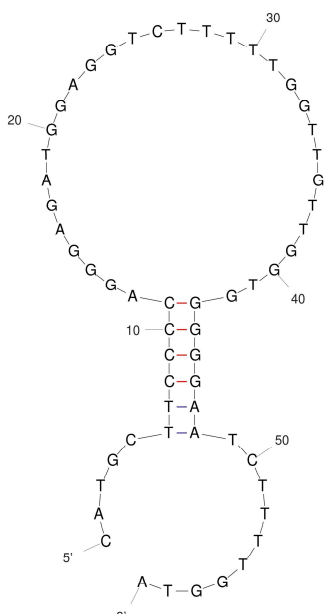

$\mathbf{F}$
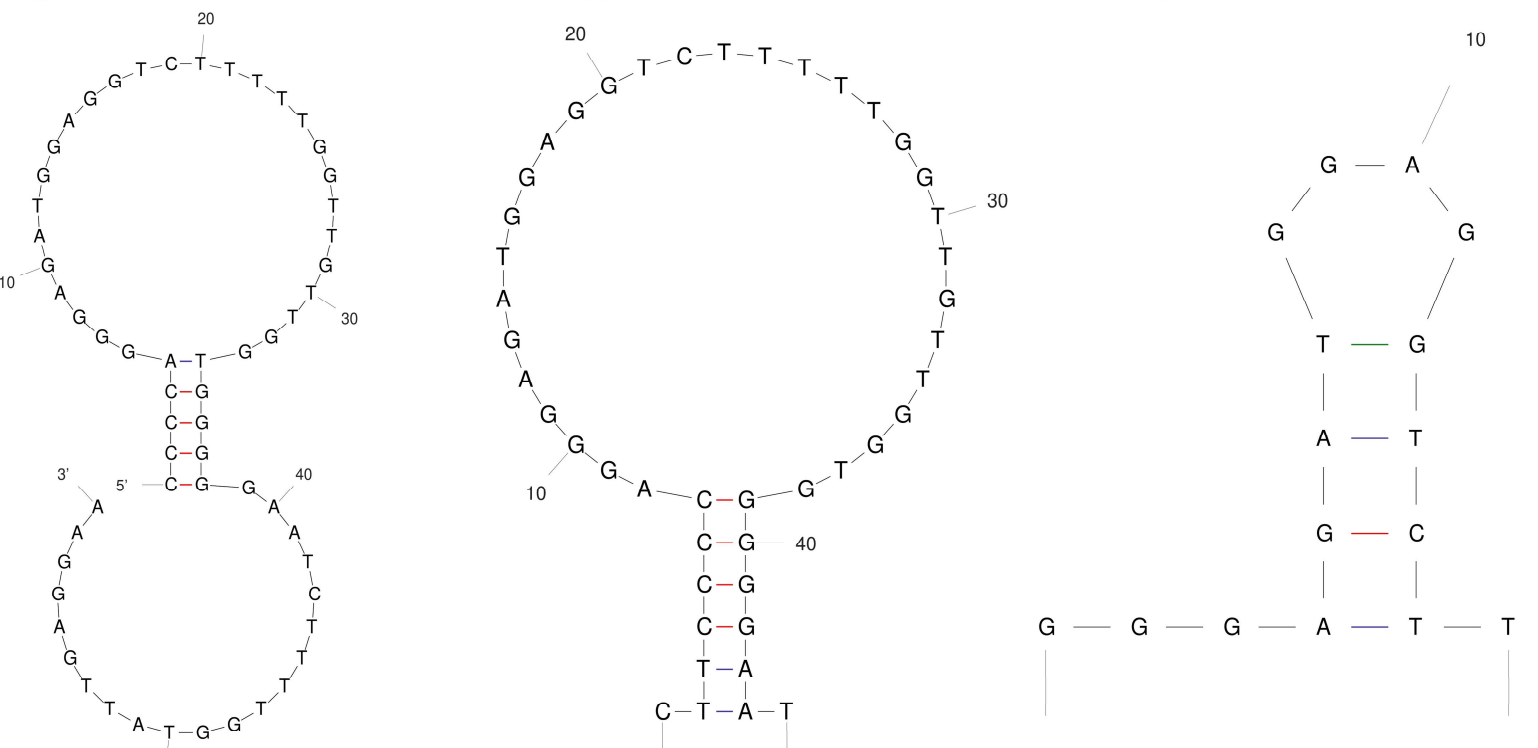

Figure 2. Secondary structures of the original $\alpha$-amanitin aptamer and the truncated aptamer. The secondary structures of the aptamers were predicted and analyzed using Mfold software. (A-F) are Apt, Apt-2, Apt-8, Apt-10, Apt-11, and Apt-12. 
Table 1. Primitive and truncated aptamer sequences $\left(5^{\prime}-3^{\prime}\right)$, dissociation constants $(\mathrm{Kd})$, and dG values.

\begin{tabular}{|c|c|c|c|}
\hline Name & Sequence $\left(5^{\prime}-3^{\prime}\right)$ & $\mathrm{Kd}(\mathrm{Nm})$ & dG \\
\hline Apt [39] & $\begin{array}{c}\text { CATGCTTCCCCAGGGAGATGGAGGTCTTTTTGGTTGTTGG } \\
\text { TGGGGGAATCTTTTGGTATTGAGGAACATG }\end{array}$ & $33.6 \pm 3.928$ & -3.13 \\
\hline Apt-2 & $\begin{array}{c}\text { CCAGGGAGATGGAGGTCTTTTTGGTTGTTGGTGGGGGA } \\
\text { ATCTTTTGGTATTGAGGAACATG }\end{array}$ & $37.9 \pm 6.053$ & -1.16 \\
\hline Apt-8 & $\begin{array}{c}\text { CATGCTTCCCCAGGGAGATGGAGGTCTTTTTGGTTGT } \\
\text { TGGTGGGGGAATCTTTTGGTA }\end{array}$ & $130.9 \pm 31.1$ & -3.13 \\
\hline Apt-10 & $\begin{array}{c}\text { CCCCAGGGAGATGGAGGTCTTTTTGGTTGTTGGTGGGGG } \\
\text { AATCTTTTGGTATTGAGGAA }\end{array}$ & $108.7 \pm 18.23$ & -2.41 \\
\hline $\begin{array}{l}\text { Apt-11 } \\
\text { Apt-12 }\end{array}$ & $\begin{array}{l}\text { CTTCCCCAGGGAGATGGAGGTCTTTTTGGTTGTTGGTGGGGGAAT } \\
\text { GGGAGATGGAGGTCTT }\end{array}$ & $\begin{array}{l}184.4 \pm 37.08 \\
185.2 \pm 60.87\end{array}$ & $\begin{array}{l}-3.13 \\
-0.25\end{array}$ \\
\hline
\end{tabular}

\subsection{Specificity and Affinity Testing of the Aptamer}

It has been shown that truncating to remove the excess aptamer bases improves the affinity of the aptamer. Truncated 38-nt and 12-nt aptamers specific for BPA were obtained through rational truncation from the 63-nt BPA aptamer. The dissociation constants $(\mathrm{Kd})$ of the 38-nt and 12-nt aptamers were $13.17 \mathrm{nM}$ and $27.05 \mathrm{nM}$ [40]. Compared with the 66-nt aptamer, the 38-nt aptamer was shorter and had a higher sensitivity, better selectivity, and shorter detection time than 8-hydroxyguanine [41]. The secondary structure was predicted with Mfold, and the Gibbs free energy values of the six sequences are shown in Table 1. The affinity constants of the six sequences were analyzed (Figure 3A). As the aptamer concentration increased, protection of the AuNPs by the aptamer was enhanced. When the AuNPs encountered $\mathrm{NaCl}$, the AuNPs maintained the original red color, and the higher the affinity, the more obvious the colloidal gold coagulation. Aptamer affinity was analyzed using GraphPad Prism 8 software, and the Kd values of Apt, Apt-2, Apt-8, Apt-10, Apt-11, and Apt-12 were $33.6 \pm 3.928,37.9 \pm 6.053,130.9 \pm 31.1,108.7 \pm 18.23,184.4 \pm 37.08$, and $132.1 \pm 32.99 \mathrm{nM}$, respectively. The results showed that the affinity constants of the original sequences were the smallest, and the affinity constants of the truncated sequences were all higher than those of the original sequences. Previous studies have shown that the lower the affinity constant, the higher the affinity; therefore, the affinity of the truncated sequence was lower than that of the original sequence.

Isothermal titration calorimetry (ITC) is an effective method for characterizing aptamer binding [42]. The aptamer was gradually titrated into $\alpha$-amanitin, and the amount of heat release was recorded as a function of time. With the addition of aptamer, the binding of aptamer and $\alpha$-amanitin gradually tends to saturate. Therefore, the amplitude of heat change will gradually become smaller and the heat signal will gradually weaken, and the final titration curve will show an " $\mathrm{S}$ " curve. The results are shown in Figure 3C-I (SourceData in Supplementary Materials Table S1). There was no caloric change in the control group, and the truncated aptamer had a different binding ability to $\alpha$-amanitin. With the help of MicroCal PEAQ-ITC Analysis Software, the Kd values, number of binding sites $(\mathrm{N})$, and each thermodynamic reaction parameter were calculated, as shown in Table 2. In conclusion, the original aptamer had desirable affinity and the results were consistent with the AuNPs assay.

As the color changed from red to violet-blue, the absorbance of the AuNPs at $520 \mathrm{~nm}$ decreased and the absorbance of the new peak at $620 \mathrm{~nm}$ increased. The absorbance values at $620 \mathrm{~nm}$ and $520 \mathrm{~nm}$ represent the state of the AuNPs [43]. Therefore, A620/A520 was used to evaluate the specificity of the aptamer to the target. The larger the A620/A520 value, the higher the specificity of the aptamer. The results of specificity analysis are shown in Figure 3B. The truncated sequence cross-reacted with non-specific targets and had no specific recognition for $\alpha$-amanitin. The original sequence did not cross-react with non-specific targets, and did not accurately identify $\alpha$-amanitin or $\beta$-amanitin. 

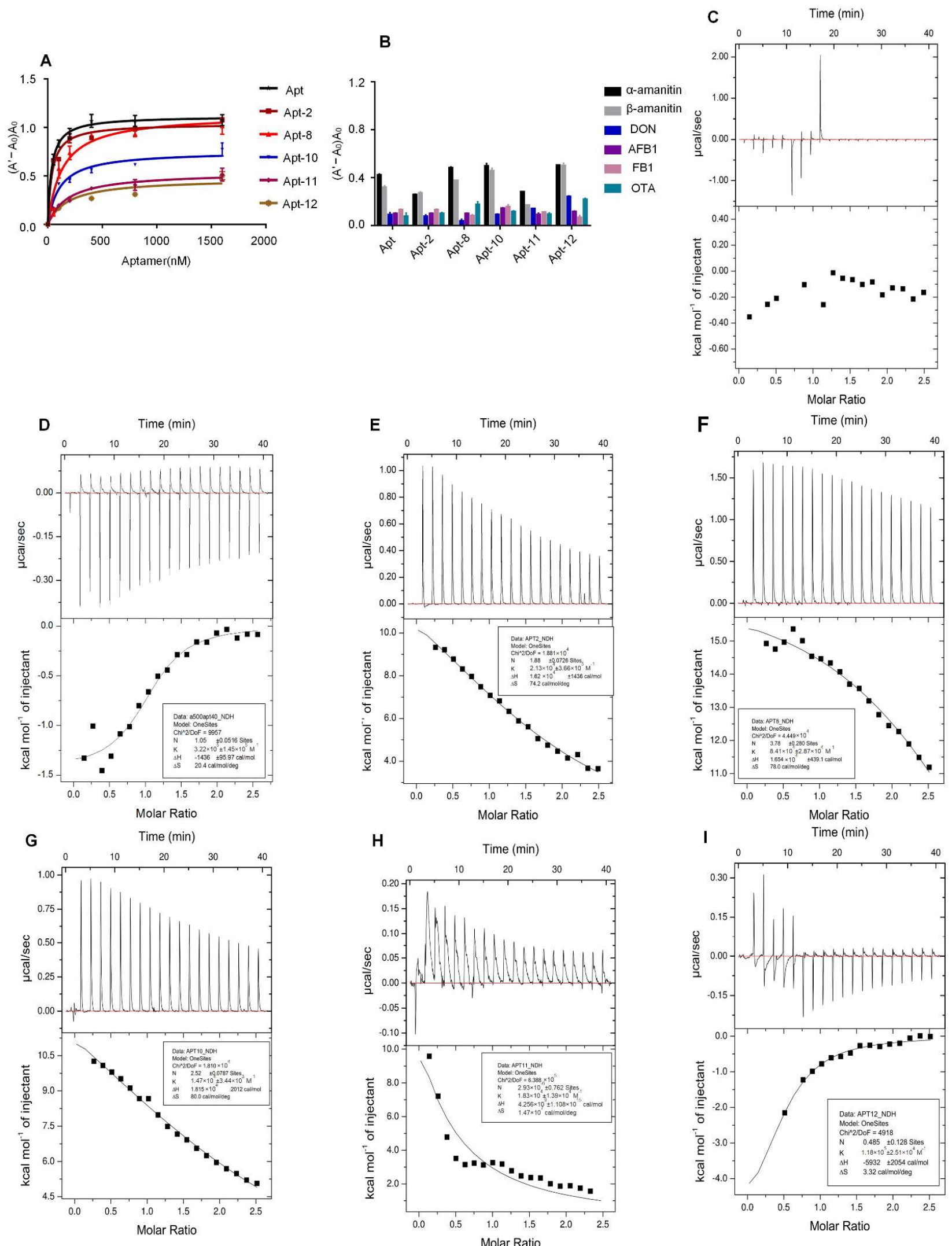

Figure 3. Haracterization of the $\alpha$-amanitin aptamer and truncated aptamer. (A) Determining $\alpha$ amanitin aptamer and truncated aptamer affinity. The aptamer concentrations $(0,50,100,200,400$, 800 , and $1600 \mathrm{nM})$ were combined with equal amounts of $\alpha$-amanitin $(1 \mu \mathrm{g} / \mathrm{mL})$, and the Kd values 
were analyzed by non-linear regression analysis using GraphPad Prism 8 software. (B) Specific test of aptamers with $\alpha$-amanitin and other non-targets ( $\beta$-amanitin, DON, AFB1, FB1, OTA). (C) Blank control: ITC results for titration of $\alpha$-amanitin with ultrapure water. (D-I) ITC results of aptamer titration of $\alpha$-amanitin.

Table 2. ITC results for original aptamer and truncated aptamer.

\begin{tabular}{cccccc}
\hline Aptamer & $\mathbf{N}($ Sites $)$ & $\mathbf{K d}(\boldsymbol{\mu M})$ & $\begin{array}{c}\Delta \mathbf{H} \\
(\mathbf{k c a l} / \mathbf{m o l})\end{array}$ & $\begin{array}{c}\Delta \mathbf{G} \\
(\mathbf{k c a l} / \mathbf{m o l})\end{array}$ & $\begin{array}{c}-\mathbf{T} \Delta \mathbf{S} \\
\mathbf{( k c a l / m o l})\end{array}$ \\
\hline Apt & 1.05 & 3.1 & -1.436 & -7.515 & -6.079 \\
Apt-2 & 1.88 & 46.9 & 16.21 & -5.36 & -2.157 \\
Apt-8 & 3.78 & 11.9 & 16.54 & -2.7 & -23.24 \\
Apt-10 & 2.52 & 68 & 18.15 & 5.69 & -23.84 \\
Apt-11 & $2.93 \times 10^{4}$ & 54.6 & $4.256 \times 10^{6}$ & $-0.124 \times 10^{6}$ & $4.38 \times 10^{6}$ \\
Apt-12 & 0.485 & 84.7 & -5.932 & -6.921 & 0.989 \\
\hline
\end{tabular}

In conclusion, the affinity and specificity of the aptamers decreased after truncation, so the original sequence was selected for subsequent research. The aptamer of CAP was removed 20 bases from the right primer region, to obtain the aptamer LR20, consisting of 40 bases, which has a higher affinity than L20; therefore, the aptamer primer region does not participate in the binding process [44]. Moreover, the deletion of the $7 \mathrm{bp}$ region of the FiPA6-ThT stem segment, the FiPA6B-ThT sensor, showed a similar fluorescent signal, indicating the importance of this loop for the stem FiPA6 aptamer [45]. Previous studies have also shown that the binding affinity of the aptamer to AFB1 requires an appropriate number of base pairs in the stem region, which contributes to the formation of a stable stem-loop structure [46]. Therefore, the region of the aptamer that binds to the target is located in the stem-loop structure. Furthermore, molecular docking was used to simulate the binding sites of aptamers to $\alpha$-amanitin, and the results are shown in Figure 4 for T3, G4, C5, T6, T7, C67, and A68, where the binding sites are located at both ends, while the optimized aptamer sequence by means of truncation at both ends is not suitable for all aptamers. Thus, the binding region of the aptamer to $\alpha$-amanitin is located on both terminal arms and at the stem end adjacent to the ring, providing new ideas for subsequent studies of aptamer truncation.

A

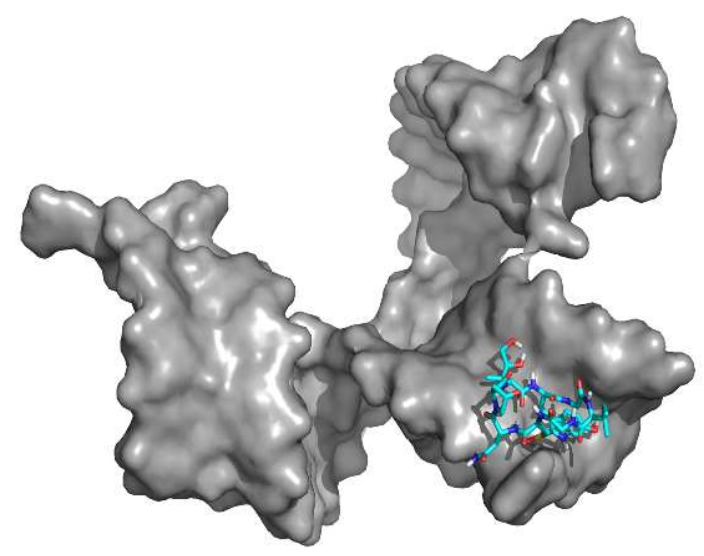

B

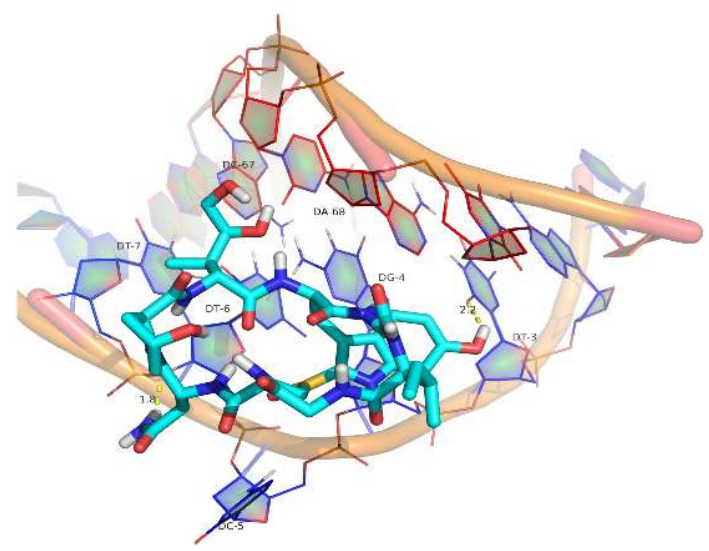

Figure 4. The interactive mechanism between the aptamer and $\alpha$-amanitin was investigated by the molecular docking simulation technique. (A) Schematic diagram of $\alpha$-amanitin binding to the aptamer (autodock mapping). (B) Base sites of the interaction between $\alpha$-amanitin and the aptamer (pymol mapping). 


\subsection{Optimization of the Experimental Conditions}

The aptamer concentration directly affected the $\alpha$-amanitin capture concentration. Figure 5A (SourceData in Supplementary Materials Table S2)shows that when the aptamer concentration was increased, the amount of aptamer immobilized on the magnetic beads increased. At this point, the absorbance value at $450 \mathrm{~nm}$ increased continuously until the aptamer concentration reached $100 \mathrm{nM}$, indicating that the aptamer concentration saturation was reached when the quantitative $\alpha$-amanitin, complementary chain, and SA-HRP were added. Therefore, the optimum concentration of aptamer was chosen as $100 \mathrm{nM}$.
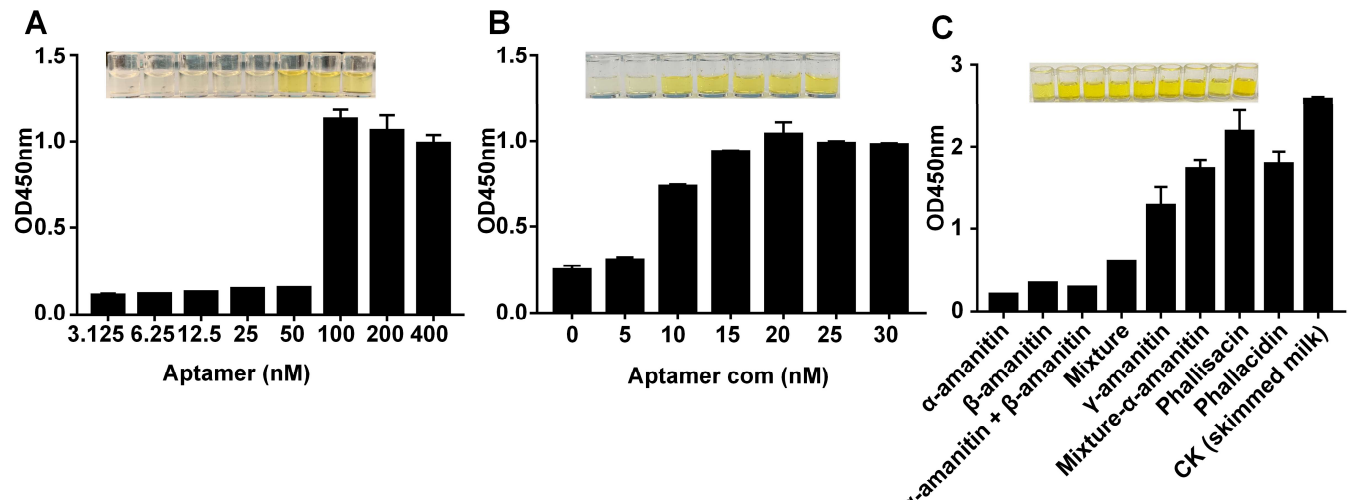

Figure 5. Optimizing the MELISA to detect $\alpha$-amanitin. (A) Optimizing the aptamer concentration. The aptamer concentrations were $3.125,6.25,12.5,25,50,100,200$, and $400 \mathrm{nM}$, in that order. (B) Optimizing the complementary chain concentrations. The complementary chain concentrations were $0,5,10,15,20,25$, and $30 \mathrm{nM}$, in that order. (C) Specificity of the experimental methods. Method specificity was determined with $\alpha$-amanitin and other non-target substances, including $\beta$-amanitin, $\gamma$-amanitin, phallacidin, and phallisacin.

This experiment was based on the competition between the complementary chains of the aptamer and the $\alpha$-amanitin, to achieve quantitative detection of $\alpha$-amanitin. The more complementary chains bound to the aptamer, the higher the absorbance value at $450 \mathrm{~nm}$. The concentration of the complementary chain was optimized in the experiment. As shown in Figure 5B, when the concentration of the aptamer complementary chain was 0-30 nM, the absorbance value of the solution at $450 \mathrm{~nm}$ increased continuously, and when the concentration reached $20 \mathrm{nM}$, the absorbance value reached saturation; thus, $20 \mathrm{nM}$ was chosen as the optimum concentration for the aptamer complimentary chain.

\subsection{Detecting $\alpha$-Amanitin with the Aptamer-Based MELISA}

To test the specificity of the MELISA, the structural analogs $\beta$-amanitin, $\gamma$-amanitin, phallacidin, and phallisacin were selected as negative controls, at a final concentration of $500 \mathrm{ng} / \mathrm{mL}$, and skimmed milk was selected as the blank. The mixture included the following five targets: $\alpha$-amanitin, $\beta$-amanitin, $\gamma$-amanitin, phallacidin, and phallisacin. The absorbance values of the other targets were compared to the blank. (Figure 5C). However, as the structures of $\beta$-amanitin and $\alpha$-amanitin are very similar, and the difference in structural formula of the two is only the difference between - $\mathrm{NH} 2$ and -OH on the R3 arm, this method specifically detected $\alpha$-amanitin compared to other biotoxins. This method can be used to specifically detect $\alpha$-amanitin, but cannot accurately distinguish $\alpha$-amanitin from $\beta$-amanitin. However, $\alpha$-amanitin and $\beta$-amanitin are almost always present in mushrooms at comparable concentrations, so both analytes are biomarkers for detecting mushroom toxin poisoning [47]. Subsequent studies should be conducted to obtain specific aptamers for $\alpha$-amanitin and to accurately differentiate $\alpha$-amanitin from $\beta$-amanitin by reverse systematic evolution of ligands, by exponential enrichment to improve aptamer specificity.

The sensitivity of the assay was evaluated using the optimized conditions, and a series of standard $\alpha$-amanitin solutions at different concentrations were measured. As the concen- 
tration of $\alpha$-amanitin was increased, $\alpha$-amanitin competed for more aptamers, resulting in fewer complementary chains bound to the aptamer and a decrease in the absorbance value of the solution at $450 \mathrm{~nm}$. As shown in Figure 6A (SourceData in Supplementary Materials Table S3), the absorbance value at $450 \mathrm{~nm}$ showed a linear relationship with the $\alpha$-amanitin concentration in the range of $0.1-6 \mu \mathrm{g} / \mathrm{mL}$, and the calibration curve equation was $\mathrm{y}=$ $-0.2708 x+1.8725\left(R^{2}=0.99\right)$. This method was able to detect $\alpha$-amanitin at a minimum of $0.1 \mu \mathrm{g} / \mathrm{mL}$. Therefore, the limit of detection of the method was $0.1 \mu \mathrm{g} / \mathrm{mL}$.
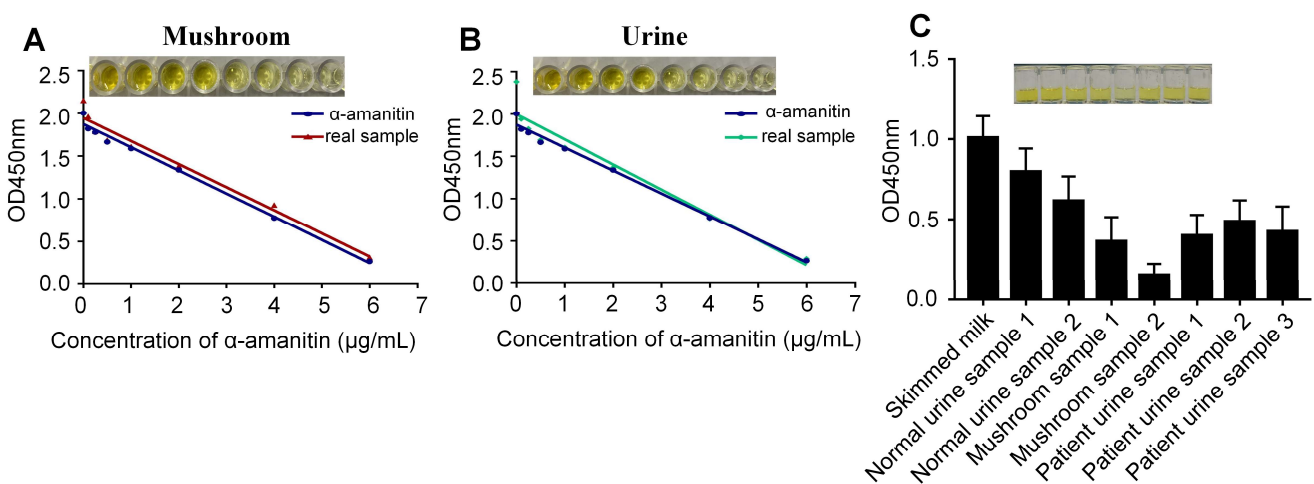

Figure 6. Experimental method validation. (A) Sensitivity detection. The concentrations of $\alpha$ amanitin in standard and mushroom were $0,0.1,0.25,0.5,1,2,4$, and $6 \mu \mathrm{g} / \mathrm{mL}$, and the corresponding OD450 values were used to prepare the standard curve. Standard curve of $\alpha$-amanitin in mushroom: $y=-0.2701 x+1.945\left(R^{2}=0.969\right)$. (B) The concentrations of $\alpha$-amanitin in standard and urine were 0 , $0.1,0.25,0.5,1,2,4$, and $6 \mu \mathrm{g} / \mathrm{mL}$, and the corresponding OD450 values were used to prepare the standard curve. Standard curve of $\alpha$-amanitin in urine: $y=-0.2969 x+1.996\left(R^{2}=0.94\right)$. (C) Determination of $\alpha$-amanitin in the actual samples. Samples (mushroom leachate and urine) were tested with skim milk as a blank control.

Compared with traditional ELISA [15], the magnetic bead-based enzyme linked immunoassay(MELISA) saves time and cost by immobilizing the aptamer and capturing the target with the help of magnetic beads. In addition, this method is highly sensitive and specific, does not require professionals to operate, and provides a reference for detecting other toxins. This method utilizes the targeted recognition function of the aptamer to achieve specific detection of $\alpha$-amanitin, and the combination of streptavidin and biotin greatly improved the immobilization efficiency of the aptamer. In addition, the use of streptavidin magnetic beads allowed for separation and enrichment, making the method convenient. The detection limit of the magnetic bead-based enzyme linked immunoassay (MELISA) needs to be improved compared to the monoclonal antibody-based method for detecting amatoxin [16-18]. However, monoclonal antibodies take a long time to prepare and require high upfront costs. Therefore, the aptamer was used to replace the antibody, to establish a new method for detecting amatoxin, which greatly saves time and cost.

\subsection{Detecting $\alpha$-Amanitin in Actual Samples}

The components of the test sample other than the analyte are called matrices, which often affect and interfere with the accuracy of the results when the sample is tested, and this is a major problem when testing actual samples. To assess matrix effects, actual samples of mushroom and urine were spiked and standard curves were established; the limit of detection in mushroom was $0.372 \mu \mathrm{g} / \mathrm{mL}$ and in urine was $0.337 \mu \mathrm{g} / \mathrm{mL}$. In general, the closer the standard curve of $\alpha$-amanitin in the actual sample is to that of the standard, the smaller the matrix effect it produces and the higher the recovery. As shown in Figure 6A,B, the mushroom and urine samples were close to the standard curve of $\alpha$-amanitin. Furthermore, as shown in Table 3 , the spiked recoveries of $\alpha$-amanitin in mushroom was $84-95 \%$ and $83-96 \%$ in urine using commercial kits, and the spiked recoveries of $\alpha$-amanitin in mushroom was $85-97 \%$ and $86-96 \%$ in urine using MELISA. 
The samples (mushroom leachate and urine) were tested using skim milk as the blank control, to further verify the feasibility of the method. The results are shown in Figure $6 \mathrm{C}$ and Table 4 . The absorbance values of the mushroom leachate and patient urine samples at $450 \mathrm{~nm}$ were significantly lower $(p<0.05)$ than those of the blank control, and the results were consistent with HPLC, demonstrating that the method can detect $\alpha$-amanitin in actual samples.

Table 3. The detected concentrations of $\alpha$-amanitin were compared with the standards added to the actual samples.

\begin{tabular}{cccccc}
\hline Samples & $\begin{array}{c}\text { Added Concentration } \\
(\mathbf{n g} / \mathbf{m L})\end{array}$ & $\begin{array}{c}\text { Kit Measured } \\
(\mathbf{n g} / \mathbf{m L})\end{array}$ & $\begin{array}{c}\text { Recovery } \\
\mathbf{( \% )}\end{array}$ & $\begin{array}{c}\text { MELISA } \\
(\mathbf{n g} / \mathbf{m L})\end{array}$ & $\begin{array}{c}\text { Recovery } \\
\mathbf{( \% )}\end{array}$ \\
\hline \multirow{4}{*}{ Mushroom } & 10 & 8.413 & 84.13 & 8.951 & 89.51 \\
& 50 & 47.14 & 94.28 & 42.85 & 85.7 \\
& 100 & 90.48 & 90.48 & 88.16 & 88.16 \\
Urine & 200 & 191.3 & 95.65 & 194.8 & 97.4 \\
& 10 & 8.304 & 83.04 & 8.94 & 89.4 \\
& 50 & 46.46 & 92.92 & 43.08 & 86.1 \\
& 100 & 90.21 & 90.21 & 90.16 & 90.16 \\
& 200 & 192.93 & 96.46 & 192.6 & 96.3 \\
\hline
\end{tabular}

Table 4. Comparison of two detection methods.

\begin{tabular}{ccc}
\hline Sample & Magnetic Bead-ELISA $(\boldsymbol{n = 2 )}$ & HPLC $(\boldsymbol{n = 2 )}$ \\
\hline Normal urine sample1 & -- & -- \\
Normal urine sample2 & -- & -- \\
Mushroom sample1 & ++ & ++ \\
Mushroom sample2 & ++ & ++ \\
Patient urine sample1 & ++ & ++ \\
Patient urine sample2 & ++ & ++ \\
Patient urine sample3 & ++ & ++ \\
\hline
\end{tabular}

The traditional methods for detecting amatoxin are instrumental assays and liquid chromatography mass spectrometer (LC-MS). ELISA detects analytes in the $\mathrm{ng} / \mathrm{mL}$ range [48-50]. The use of LC-MS requires complex sample pretreatment and expensive instrumentation. Previous studies have reported the development of a competition-based lateral flow immunoassay (LFIA) for the rapid, portable, selective, and sensitive detection of amatoxin, where extraction and detection can be accomplished in approximately $10 \mathrm{~min}[17,18]$. This assay can be easily observed by eye and does not require instrumental reading. However, the LFIA is susceptible to false-positive and false-negative results due to storage conditions and matrix effects.

Due to the rapid metabolism of amatoxin in urine, many methods cannot be used to detect amatoxin in urine; therefore, a rapid method for detecting amatoxin in urine samples is needed. The MELISA is not affected by the sample matrix effect and can detect $\alpha$-amatoxin in mushroom samples and urine, providing ideas for the development of clinical detection technology.

\subsection{Molecular Docking Simulation Results}

To investigate the interactive mode between $\alpha$-amanitin and the aptamer, we predicted and analyzed the binding sites using molecular docking technology. The mutual recognition and specific non-covalent binding of the aptamer to $\alpha$-amanitin occurred by hydrophobic interactions, van der Waals forces, and hydrogen bonding, and the minimum binding energy of $\alpha$-amanitin molecule with aptamer was $-4.26 \mathrm{kal} / \mathrm{M}$. The results are shown in Figure 4 . When $\alpha$-amanitin bound specifically to the aptamer, it did not interact with all base sites of the aptamer, but only with the base sites at specific positions, such as T3, G4, C5, T6, T7, C67, and A68 of the single-stranded oligonucleotide. The hydrogen atoms on 
the $\alpha$-amanitin ligand formed hydrogen bonds with oxygen atoms on the base of the T3 aptamer with a length of $2.2 \mathrm{~A}$, while the amino hydrogen atoms formed hydrogen bonds with oxygen atoms in the skeleton between T6 and T7, with a length of $1.8 \mathrm{~A}$.

Molecular simulations, to study the interactions between ligand and receptor molecules, help to understand the recognition and binding mechanisms, while providing a reference for subsequent mechanistic studies. Molecular simulation experiments are an auxiliary tool to study the binding sites between aptamers and targets, elucidate the structures of the aptamer-target complexes, and determine the binding pockets of the aptamers and targets, to more accurately describe the binding mechanism.

\section{Conclusions}

In this study, an aptamer was truncated to remove the redundant arms of the original $\alpha$ amanitin aptamer, retain the loop structure, and truncate it into five different sequences. The affinity and specificity of the original aptamer and the truncated aptamer were identified. The results showed that the affinity and specificity of aptamers decreased after truncation. The aptamer affinity and specificity identification and molecular docking predicted the binding site of the aptamer to $\alpha$-amanitin, indicating that the binding region of the aptamer to $\alpha$-amanitin is located on the arm and at the stem end adjacent to the ring. Therefore, a novel method for detecting $\alpha$-amanitin was established, using the original aptamer. An aptamer-based MELISA was developed, based on the traditional ELISA technique. The absorbance value at $450 \mathrm{~nm}$ was linearly related to the concentration in the range of $0.1-6 \mu \mathrm{g} / \mathrm{mL}$, and the detection limit was $0.369 \mu \mathrm{g} / \mathrm{mL}$, while in mushroom it was $0.372 \mu \mathrm{g} / \mathrm{mL}$, and in urine $0.337 \mu \mathrm{g} / \mathrm{mL}$. The use of magnetic beads made the method more sensitive, less time-consuming, and more efficient than traditional ELISA. Actual samples (mushroom leachate and urine) were tested under the optimal experimental conditions, and the results were as expected and consistent with those of HPLC.

\section{Materials and Methods}

\subsection{Reagents}

DON, OTA, AFB1, FB1, HAuCl4, and sodium citrate were purchased from SigmaAldrich Co. (St. Louis, MO, USA). $\alpha$-Amanitin, $\beta$-amanitin, $\gamma$-amanitin, phallacidin, and phallisacin were obtained from the College of Life Sciences, Hunan Normal University (Changsha, China). Streptavidin-labeled magnetic beads were purchased from Primag Biotechnology Co., Ltd. (Xiamen, China). $\alpha$-amanitin ELISA Kit was purchased from Shenzhen ziker Biological Technology Co., Ltd. (Shenzhen, China). Streptavidin-labeled horseradish peroxidase and the TMB color solution were purchased from TaKaRa (Beijing, China). Aptamer sequences, as shown in Table 1, were synthesized by Beijing Optimus Biotechnology Co., Ltd. (Beijing, China).

\subsection{Preparation and Identification of the AuNPs}

The AuNP solution was prepared using the sodium citrate reduction method [51]. First, $99 \mathrm{~mL}$ of deionized water and $1 \mathrm{~mL}$ of $1 \%$ chloroauric acid solution were added to a pre-soaked, dried, and treated $250 \mathrm{~mL}$ clean conical flask, and all solutions were filtered using an ultrafiltration membrane $(0.45 \mu \mathrm{m})$. Subsequently, the solution was heated with a magnetic stirrer until it started to boil. Then, $1.5 \mathrm{~mL}$ of $1 \%$ sodium citrate solution was added quickly, the temperature of the magnetic stirrer was adjusted appropriately, and the color of the solution changed from light yellow to black, then from black to purple-red, and finally from purple-red to red. The solution was transparent. Finally, when the color of the solution no longer changed, the heating and stirring were continued for $10 \mathrm{~min}$, and the conical flask was placed at room temperature and cooled. After cooling, the solution was dispensed and transferred to $4{ }^{\circ} \mathrm{C}$ for storage. The size, shape, and homogeneity of the colloidal gold particles were characterized by transmission electron microscopy and scanning the 400-600 nm UV-vis absorption spectra. Figure 7 shows that the prepared colloidal gold solution had a single absorption peak at the detection wavelength of $520 \mathrm{~nm}$. 
No spurious peaks appeared, indicating that the prepared colloidal gold solution was homogeneous and dispersed.

A

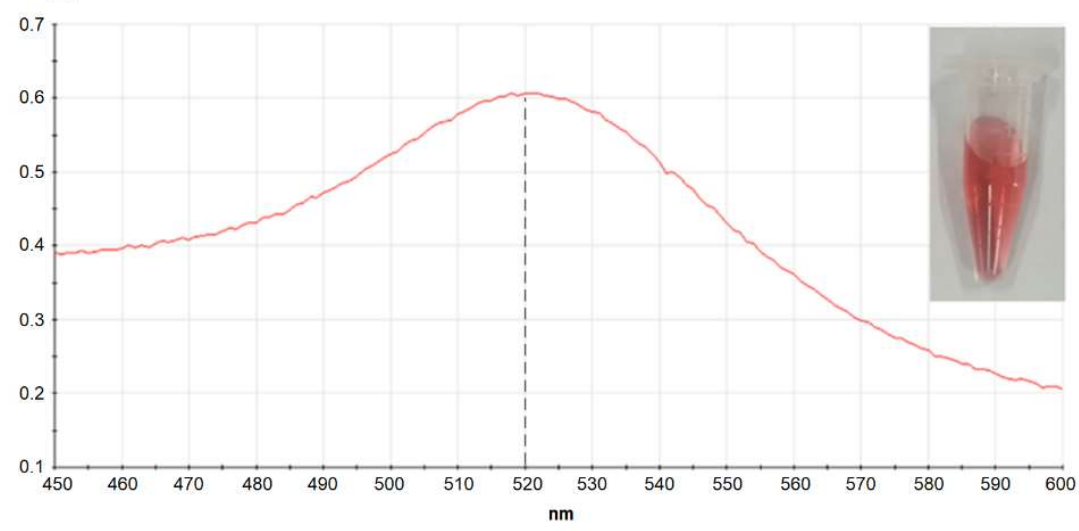

B

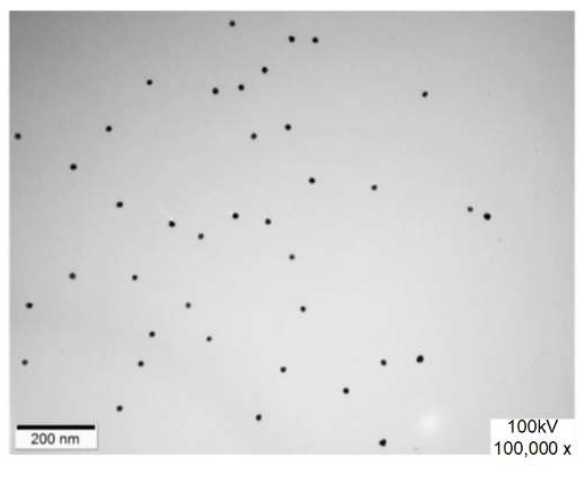

Figure 7. Characterization of colloidal gold. (A) UV-visible absorption spectra of the AuNPs. (B) TEM image of the AuNPs.

\subsection{Truncation of the Original $\alpha$-Amanitin Aptamer Sequence}

All truncated $\alpha$-amanitin aptamers were truncated and designed based on the secondary structure of the original full-length 70-mer

(5'-CATGCTTCCCCAGGGAGATGGAGGTCTTTTTGGTTGTTGGTGGGGGAATCTT TTGGTATTGAGGAACATG-3'), as reported by Muszyńska et al. [39]. Excessively long aptamer sequences with large spatial site resistance easily affect the binding of the aptamer to the target, and an excessively long aptamer is not conducive to design and practical applications, which increases the synthesis cost [52]. Therefore, in this study, the secondary structure of the $\alpha$-amanitin aptamer was simulated using Mfold software online (http:/ / www.unafold.org/mfold/applications/dna-folding-form.php, accessed on 14 May 2021), and the $5^{\prime}$ end was trimmed, the $3^{\prime}$ end was trimmed, and both ends were trimmed simultaneously on the aptamer separately [53]. The two-end simultaneous trimming was performed by removing the extra two arms based on the original sequence stem-loop structure and then trimming the base pairs until the stem-loop structure was destroyed. Single-end trimming was performed in 3-base pairs, until the stem-loop structure of the original sequence was destroyed.

\subsection{Aptamer Specificity and Affinity Tests}

Different concentrations of the aptamer $(0,50,100,200,400,800$, and $1600 \mathrm{nM})$ were incubated with $1 \mu \mathrm{g} / \mathrm{mL}$ of $\alpha$-amanitin for $30 \mathrm{~min}$ at room temperature. AuNPs were added and incubated for $30 \mathrm{~min}$ at room temperature, followed by the addition of $1 \mathrm{M} \mathrm{NaCl}$, to make a final concentration of $40 \mathrm{mM}$ [54]. Absorbance values at $520 \mathrm{~nm}$ were measured using a UV spectrophotometer (Thermo BIOMATE3S; Thermo Scientific, Waltham, MA, USA). The aptamer concentration was used as the horizontal coordinate and $\left(\mathrm{A}^{\prime}-\mathrm{A}_{0}\right) / \mathrm{A}_{0}$ was the vertical coordinate, and the aptamer affinity constants were calculated using GraphPad Prism 8.0 software (GraphPad Software Inc., La Jolla, CA, USA). A' represented the $A 520 \mathrm{~nm}$ value of the aptamer at each concentration. $\mathrm{A}_{0}$ represented the $\mathrm{A} 520 \mathrm{~nm}$ value when the aptamer concentration was zero.

Isothermal titration calorimetry (ITC) was conducted on a VPITC microcalorimeter. All solutions were degassed to avoid air bubbles. The $\alpha$-amanitin was diluted with ultrapure water to a concentration of $41.6 \mu \mathrm{M}$. Experiment temperature: $25^{\circ} \mathrm{C}$, speed: $700 \mathrm{rpm}$, a total of 20 drops, the first drop: $0.2 \mu \mathrm{L}$, the other drops: $2 \mathrm{uL}$, each drop interval: $120 \mathrm{~s}$. The titration phase: aptamers, concentration: $500 \mu \mathrm{M}(50 \mu \mathrm{L})$, and the titrated phase: $\alpha-$ amanitin, concentration: $41.6 \mu \mathrm{M}(350 \mu \mathrm{L})$. Set up a blank control: ultrapure water titrated with $\alpha$-amanitin. 
$\alpha$-Amanitin, $\beta$-amanitin, DON, AFB1, FB1, and OTA $(1 \mu \mathrm{g} / \mathrm{mL})$ were incubated with $400 \mathrm{nM}$ of the aptamer for $30 \mathrm{~min}$ at room temperature. AuNPs were added and incubated for $30 \mathrm{~min}$ at room temperature protected from light, and then $1 \mathrm{M} \mathrm{NaCl}$ was added to make a final concentration of $40 \mathrm{mM}$ [54]. Absorbance values at $520 \mathrm{~nm}$ and $620 \mathrm{~nm}$ were measured with a UV spectrophotometer (Thermo BIOMATE3S) (A520 nm and A620 nm. $\mathrm{A}^{\prime}: \alpha$-amanitin, $\beta$-amanitin, $\mathrm{DON}, \mathrm{AFB}_{1}, \mathrm{FB}_{1}$, and OTA at a concentration of $1 \mu \mathrm{g} / \mathrm{mL}$ $(\mathrm{A} 620 \mathrm{~nm} / \mathrm{A} 520 \mathrm{~nm})$ and $\mathrm{A}_{0}{ }^{\prime}:(\mathrm{A} 620 \mathrm{~nm} / \mathrm{A} 520 \mathrm{~nm})$ values without a target. The graph was plotted with $\left(\mathrm{A}^{\prime}-\mathrm{A}_{0}^{\prime}\right) / \mathrm{A}_{0}^{\prime}$ as the horizontal coordinate and the type of target as the vertical coordinate.

\subsection{Optimizing the MELISA Experimental Conditions}

Determining the optimal concentration of the aptamer was a key part of this experiment, as too low an aptamer concentration would lead to insignificant changes in absorbance values, and too high an aptamer concentration would lead to higher costs. First, the magnetic beads were cleaned twice with a magnetic bead combined buffer, and the volume in each tube after the last cleaning was $50 \mu \mathrm{L}$. The magnetic beads were resuscitated with a fit combination buffer of $3.125,6.25,12.5,25,50,100,200$, and $400 \mathrm{nM}$, respectively, and gently shaken at room temperature for $15 \mathrm{~min}$. The supernatant was discarded from the coupling-adapted streptavidin magnetic beads in the $1.5 \mathrm{~mL}$ centrifuge tube. Skim milk was added at $37^{\circ} \mathrm{C}$, and the tubes were closed for $2 \mathrm{~h}$. A $100 \mu \mathrm{L}$ aliquot of $\alpha$-amanitin (final concentration of $500 \mathrm{ng} / \mathrm{mL}$ ) was added to each tube and incubated at $37^{\circ} \mathrm{C}$ for $2 \mathrm{~h}$. A $100 \mu \mathrm{L}$ aliquot of the aptamer-labeled complementary chain $(20 \mathrm{nM})$ with a biotin label was added and incubated for $1 \mathrm{~h}$ at $37^{\circ} \mathrm{C}$. A $100 \mu \mathrm{L}$ portion of 1000 -fold diluted HRP was added to each tube and incubated at $37^{\circ} \mathrm{C}$ for $1 \mathrm{~h}$. The tubes were washed four times with PBST solution, after each of the above steps. A $100 \mu \mathrm{L}$ aliquot of TMB color development solution was added and incubated at $37^{\circ} \mathrm{C}$ for $15 \mathrm{~min}$ in the dark. After color development was completed, $50 \mu \mathrm{L}$ of $2 \mathrm{M} \mathrm{H} 2 \mathrm{SO} 4$ was added to each tube to terminate the reaction, and the supernatant was aspirated. The absorbance value of the supernatant solution was measured at $450 \mathrm{~nm}$ within $10 \mathrm{~min}$ of terminating the reaction using an enzyme marker.

The complementary chain concentration was optimized as follows: The steps were the same as described above to optimize the aptamer concentration, except for the first and fourth steps. First, the aptamer (final concentration $100 \mathrm{nM}$ ) was added. A $100 \mu \mathrm{L}$ aliquot of different concentrations of the complementary chain solutions $(0,5,10,15,20,25$, and $30 \mathrm{nM}$ ) was added to each tube. All other conditions were the same as above.

\subsection{Detecting $\alpha$-Amanitin Using the Aptamer-Based MELISA}

The specificity of an assay is key to verifying the feasibility of the method. Therefore $\beta$ amanitin and $\gamma$-amanitin were the structural analogs used under the optimized conditions. Phallacidin and phallisacin were used as negative controls, and skimmed milk was used as the blank control for the specificity study. The mixture of the five toxins was tested.

Different $\alpha$-amanitin concentrations were assayed and linear curves were established to investigate the sensitivity of the method. Under the optimized conditions, the third step was changed to add $\alpha$-amanitin at final concentrations of $0,0.1,0.25,0.5,1,2,4$, and $6 \mu \mathrm{g} / \mathrm{mL}$ and incubated at $37^{\circ} \mathrm{C}$ for $2 \mathrm{~h}$.

\subsection{Preparation of the Samples}

In order to assess the effect of the matrix on the assay, both mushroom and urine matrices were used for the determination of the sensitivity of $\alpha$-amanitin. The standards of $\alpha$-amanitin with the same concentration $(0,0.1,0.25,0.5,1,2,4$, and $6 \mu \mathrm{g} / \mathrm{mL})$ as the standard curve were added to the normal urine and mushroom leachate, respectively, and the concentration of $\alpha$-amanitin in the spiked samples was calculated with reference to the standard curve, and the recoveries were calculated. Three replicates of the experiment were performed for each group. The spiked samples were detected using a commercial kit 
for $\alpha$-amanitin, and the experimental procedures were carried out in accordance with the instructions. The difference in recovery between MELISA and the ELISA kit was compared.

To further verify the feasibility of the method for detecting the compounds in actual samples, mushroom leachate and urine were tested using the method, and the results were compared with the national standard of high-performance liquid chromatography (HPLC). Normal human urine was used as the negative control and skimmed milk was the blank control in the experiment. The samples were pretreated as follows: one-third of a cap of an amatoxin sample was taken in a mortar, $8 \mathrm{~mL}$ of water was added for grinding, and the supernatant was centrifuged; the total volume of the supernatant was $5.7 \mathrm{~mL}$. The processed amatoxin leachate was subsequently removed for gradient dilution and set aside. Skim milk, the mushroom leachate, a urine sample from a poisoned patient, and a normal urine sample was added and incubated in $20 \mu \mathrm{L}$, which was brought up to $100 \mu \mathrm{L}$ with $5 \%$ skim milk and incubated at $37^{\circ} \mathrm{C}$ for $2 \mathrm{~h}$.

\subsection{Molecular Docking Simulation}

Molecular docking has been widely used to explore and model how ligand and receptor molecules recognize each other. Molecular docking simulation focuses on the interaction between two molecules to predict the simulated binding mechanism $[55,56]$. In this study, molecular docking simulations were performed to further understand the recognition sites between the aptamer and $\alpha$-amanitin. First, the 3D structure of the aptamer was obtained from online modeling. Then, simulation operations were performed using Autodock software.

Supplementary Materials: The following are available online https://www.mdpi.com/article/10 .3390/molecules27020538/s1. Table S1: SourceData in Figure 3; Table S2: SourceData in Figure 5; Table S3: SourceData in Figure 6.

Author Contributions: Conceptualization, Q.H.; methodology, Q.H.; validation, Q.H., J.G., N.L. and X.Z.; formal analysis, Q.H. and J.G.; investigation, Q.H.; resources, Q.H., Y.S., E.Y. and J.Z.; data curation, Q.H.; writing — original draft preparation, J.G.; writing—review and editing, Q.H. and J.G.; visualization, J.G.; supervision, Q.H.; project administration, Q.H.; funding acquisition, Q.H. and E.Y. All authors have read and agreed to the published version of the manuscript.

Funding: This research was funded by National Natural Science Foundation of China (NSFC Grant No. 32160601) and Basic research projects of Yunnan Province (No. 202001AT070033, 140520210031).

Institutional Review Board Statement: Not applicable.

Informed Consent Statement: Written informed consent has been obtained from the patient(s) to publish this paper.

Data Availability Statement: The data presented in this study are available in supplementary material.

Acknowledgments: To Kunming University of Science and Technology for providing all the facilities for this research and to Natural Science Foundation of China (NSFC Grant No. 32160601) and Basic research projects of Yunnan Province (No. 202001AT070033, 140520210031) for financial support.

Conflicts of Interest: The authors declare no conflict of interest.

\section{References}

1. Diaz, J.H. Amatoxin-Containing Mushroom Poisonings: Species, Toxidromes, Treatments, and Outcomes. Wilderness Environ. Med. 2018, 29, 111-118. [CrossRef] [PubMed]

2. $\mathrm{Yu}, \mathrm{C} . ; \mathrm{Li}, \mathrm{H}$. Expert consensus on clinical diagnosis and treatment of mushroom poisoning with amanita in China (in Chinese). hinese J. Crit. Care Med. (Electron. Ed.) 2020, 13, 20-28.

3. Santi, L.; Maggioli, C.; Mastroroberto, M.; Tufoni, M.; Napoli, L.; Caraceni, P. Acute Liver Failure Caused by Amanita phalloides Poisoning. Int. J. Hepatol. 2012, 2012, 487480. [CrossRef] [PubMed]

4. Michelot, D.; Melendez-Howell, L.M. Amanita muscaria: Chemistry, biology, toxicology, and ethnomycology. Mycol. Res. 2003, 107, 131-146. [CrossRef]

5. Brueckner, F.; Cramer, P. Structural basis of transcription inhibition by alpha-amanitin and implications for RNA polymerase II translocation. Nat. Struct. Mol. Biol. 2008, 15, 811-818. [CrossRef] [PubMed] 
6. Kaya, E.; Yilmaz, I.; Admis, O.; Oktay, M.; Bayram, R.; Bakirci, S.; Yaykasli, K.O.; Kandis, H.; Saritas, A.; Katirci, Y.J.T.R. Effects of erdosteine on alpha amanitin-induced hepatotoxicity in mice. Toxin Rev. 2016, 35, 4-9. [CrossRef]

7. Garcia, J.; Costa, V.M.; Carvalho, A.T.; Silvestre, R.; Duarte, J.A.; Dourado, D.F.; Arbo, M.D.; Baltazar, T.; Dinis-Oliveira, R.J.; Baptista, P.; et al. A breakthrough on Amanita phalloides poisoning: An effective antidotal effect by polymyxin B. Arch. Toxicol. 2015, 89, 2305-2323. [CrossRef]

8. Brandenburg, W.E.; Ward, K.J. Mushroom poisoning epidemiology in the United States. Mycologia 2018, 110, 637-641. [CrossRef]

9. Butera, R.; Locatelli, C.; Coccini, T.; Manzo, L. Diagnostic accuracy of urinary amanitin in suspected mushroom poisoning: A pilot study. J. Toxicol. Clin. Toxicol. 2004, 42, 901-912. [CrossRef]

10. Sun, J.; Niu, Y.M.; Zhang, Y.T.; Li, H.J.; Yin, Y.; Zhang, Y.Z.; Ma, P.B.; Zhou, J.; Huang, L.; Zhang, H.S.; et al. Toxicity and toxicokinetics of Amanita exitialis in beagle dogs. Toxicon: Off. J. Int. Soc. Toxinol. 2018, 143, 59-67. [CrossRef]

11. Garcia, J.; Costa, V.M.; Baptista, P.; Bastos Mde, L.; Carvalho, F. Quantification of alpha-amanitin in biological samples by HPLC using simultaneous UV-diode array and electrochemical detection. J. Chromatogr. B Anal. Technol. Biomed. Life Sci. 2015, 997, 85-95. [CrossRef]

12. Maurer, H.H.; Kraemer, T.; Ledvinka, O.; Schmitt, C.J.; Weber, A.A. Gas chromatography-mass spectrometry (GC-MS) and liquid chromatography-mass spectrometry (LC-MS) in toxicological analysis. Studies on the detection of clobenzorex and its metabolites within a systematic toxicological analysis procedure by GC-MS and by immunoassay and studies on the detection of alpha- and beta-amanitin in urine by atmospheric pressure ionization electrospray LC-MS. J. Chromatogr. B Biomed. Sci. Appl. 1997, 689, 81-89. [PubMed]

13. Filigenzi, M.S.; Poppenga, R.H.; Tiwary, A.K.; Puschner, B. Determination of alpha-amanitin in serum and liver by multistage linear ion trap mass spectrometry. J. Agric. Food Chem. 2007, 55, 2784-2790. [CrossRef] [PubMed]

14. Abbott, N.L.; Hill, K.L.; Garrett, A.; Carter, M.D.; Hamelin, E.I.; Johnson, R.C. Detection of $\alpha$-, $\beta$-, and $\gamma$-amanitin in urine by LC-MS/MS using (15)N(10)- $\alpha$-amanitin as the internal standard. Toxicon: Off. J. Int. Soc. Toxinol. 2018, 152, 71-77. [CrossRef] [PubMed]

15. Staack, R.; Maurer, H. New Bühlmann ELISA for determination of Amanitins in urine-Are there false positive results due to interferences with ur ine matrix, drugs or their metabolites? Toxichem Krimtech 2000, 68, 68-71.

16. He, K.; Mao, Q.; Zang, X.; Zhang, Y.; Li, H.; Zhang, D. Production of a broad-specificity monoclonal antibody and application as a receptor to detection amatoxins in mushroom. Biol.: J. Int. Assoc. Biol. Stand. 2017, 49, 57-61. [CrossRef]

17. Bever, C.S.; Swanson, K.D.; Hamelin, E.I.; Filigenzi, M.; Poppenga, R.H.; Kaae, J.; Cheng, L.W.; Stanker, L.H. Rapid, Sensitive, and Accurate Point-of-Care Detection of Lethal Amatoxins in Urine. Toxins 2020, 12, 123. [CrossRef]

18. Bever, C.S.; Adams, C.A.; Hnasko, R.M.; Cheng, L.W.; Stanker, L.H. Lateral flow immunoassay (LFIA) for the detection of lethal amatoxins from mushrooms. PLoS ONE 2020, 15, e0231781.

19. Kinghorn, A.B.; Fraser, L.A.; Lang, S.; Shiu, S.C.C.; Tanner, J.A. Aptamer Bioinformatics. Int. J. Mol. Sci. 2017, 18, 2516. [CrossRef]

20. Parashar, A. Aptamers in Therapeutics. J. Clin. Diagn. Res. JCDR 2016, 10, 1-6. [CrossRef]

21. Hermann, T.; Patel, D.J. Adaptive recognition by nucleic acid aptamers. Science 2000, 287, 820-825. [CrossRef] [PubMed]

22. Wang, Q.; Yang, Q.; Wu, W. Graphene-Based Steganographic Aptasensor for Information Computing and Monitoring Toxins of Biofilm in Food. Front. Microbiol. 2019, 10, 3139. [CrossRef] [PubMed]

23. Ma, P.; Ye, H.; Deng, J.; Khan, I.M.; Yue, L.; Wang, Z. A fluorescence polarization aptasensor coupled with polymerase chain reaction and streptavidin for chloramphenicol detection. Talanta 2019, 205, 120119. [CrossRef]

24. Wang, C.; Sun, L.; Zhao, Q. A simple aptamer molecular beacon assay for rapid detection of aflatoxin B1. Chin. Chem. Lett. 2019, 30, 1017-1020. [CrossRef]

25. Trinh, K.H.; Kadam, U.S.; Song, J.; Cho, Y.; Kang, C.H.; Lee, K.O.; Lim, C.O.; Chung, W.S.; Hong, J.C. Novel DNA Aptameric Sensors to Detect the Toxic Insecticide Fenitrothion. Int. J. Mol. Sci. 2021, 22, 846. [CrossRef]

26. Moutsiopoulou, A.; Broyles, D.; Dikici, E.; Daunert, S.; Deo, S.K. Molecular Aptamer Beacons and Their Applications in Sensing, Imaging, and Diagnostics. Small (Weinh. Der Bergstr. Ger.) 2019, 15, e1902248. [CrossRef]

27. Gu, C.; Xiang, Y.; Guo, H.; Shi, H. Label-free fluorescence detection of melamine with a truncated aptamer. Analyst 2016, 141, 4511-4517. [CrossRef]

28. Le, T.T.; Chumphukam, O.; Cass, A.E. Determination of minimal sequence for binding of an aptamer. A comparison of truncation and hybridization inhibition methods. RSC Adv. 2014, 4, 47227-47233. [CrossRef]

29. Vu, C.Q.; Rotkrua, P.; Tantirungrotechai, Y.; Soontornworajit, B.J.A.C.S. Oligonucleotide Hybridization Combined with Competitive Antibody Binding for the Truncation of a High-Affinity Aptamer. ACS Comb. Sci. 2017, 19, 609-617. [CrossRef]

30. Feig, A.L. Applications of isothermal titration calorimetry in RNA biochemistry and biophysics. Biopolymers 2007, 87, 293-301. [CrossRef]

31. Slavkovic, S.; Churcher, Z.R.; Johnson, P.E. Nanomolar binding affinity of quinine-based antimalarial compounds by the cocaine-binding aptamer. Bioorganic Med. Chem. 2018, 26, 5427-5434. [CrossRef]

32. Li, J.; Hong, D.; Peng, X.; Huang, X.; Xiong, Y.J.R.A. Effect of different-sized spherical gold nanoparticles grown layer by layer on the sensitivity of an immunochromatographic assay. Rsc Adv. 2016, 6, 26178-26185. [CrossRef]

33. Aldewachi, H.; Chalati, T.; Woodroofe, M.N.; Bricklebank, N.; Sharrack, B.; Gardiner, P. Gold nanoparticle-based colorimetric biosensors. Nanoscale 2017, 10, 18-33. [CrossRef] [PubMed] 
34. Ma, Q.; Wang, Y.; Jia, J.; Xiang, Y. Colorimetric aptasensors for determination of tobramycin in milk and chicken eggs based on DNA and gold nanoparticles. Food Chem. 2018, 249, 98-103. [CrossRef]

35. Zhou, X.; Wang, L.; Shen, G.; Zhang, D.; Xie, J.; Mamut, A.; Huang, W.; Zhou, S. Colorimetric determination of ofloxacin using unmodified aptamers and the aggregation of gold nanoparticles. Mikrochim. Acta 2018, 185, 355. [CrossRef] [PubMed]

36. Liu, S.; Huang, J.; Tan, S.; Shao, C.; Xiang, J.J.I.J. Preparation of monoclonal antibodies against human NT-Pro BNP and establishment of double-antibody sandwich ELISA. Int. J. Sci. 2020, 7, 152-162.

37. Deng, Q.; Qiu, M.; Wang, Y.; Lv, P.; Wu, C.; Sun, L.; Ye, R.; Xu, D.; Liu, Y.; Gooneratne, R. A sensitive and validated immunomagnetic-bead based enzyme-linked immunosorbent assay for analyzing total T-2 (free and modified) toxins in shrimp tissues. Ecotoxicol. Environ. Saf. 2017, 142, 441-447. [CrossRef] [PubMed]

38. Lei, J.H.; Guan, F.; Xu, H.; Chen, L.; Su, B.T.; Zhou, Y.; Wang, T.; Li, Y.L.; Liu, W.Q. Application of an immunomagnetic bead ELISA based on IgY for detection of circulating antigen in urine of mice infected with Schistosoma japonicum. Vet. Parasitol. 2012, 187, 196-202. [CrossRef]

39. Muszyńska, K.; Ostrowska, D.; Bartnicki, F.; Kowalska, E.; Bodaszewska-Lubaś, M.; Hermanowicz, P.; Faulstich, H.; Strzałka, W. Selection and analysis of a DNA aptamer binding $\alpha$-amanitin from Amanita phalloides. Acta Biochim. Pol. 2017, 64, 401-406. [CrossRef]

40. Jia, M.; Sha, J.; Li, Z.; Wang, W.; Zhang, H. High affinity truncated aptamers for ultra-sensitive colorimetric detection of bisphenol A with label-free aptasensor. Food Chem. 2020, 317, 126459. [CrossRef]

41. Matulakul, P.; Vongpramate, D.; Kulchat, S.; Chompoosor, A.; Thanan, R.; Sithithaworn, P.; Sakonsinsiri, C.; Puangmali, T. Development of Low-Cost AuNP-Based Aptasensors with Truncated Aptamer for Highly Sensitive Detection of 8-Oxo-dG in Urine. ACS Omega 2020, 5, 17423-17430. [CrossRef]

42. Slavkovic, S.; Johnson, P.E. Isothermal titration calorimetry studies of aptamer-small molecule interactions: Practicalities and pitfalls. Aptamers 2018, 2, 41-51.

43. Alsager, O.A.; Alotaibi, K.M.; Alswieleh, A.M.; Alyamani, B.J. Colorimetric Aptasensor of Vitamin D3: A Novel Approach to Eliminate Residual Adhesion between Aptamers and Gold Nanoparticles. Sci. Rep. 2018, 8, 12947. [CrossRef] [PubMed]

44. Ma, P.; Guo, H.; Duan, N.; Ma, X.; Yue, L.; Gu, Q.; Wang, Z. Label free structure-switching fluorescence polarization detection of chloramphenicol with truncated aptamer. Talanta 2021, 230, 122349. [CrossRef]

45. Trinh, K.H.; Kadam, U.S.; Rampogu, S.; Cho, Y.; Yang, K.A.; Kang, C.H.; Lee, K.W.; Lee, K.O.; Chung, W.S.; Hong, J.C. Development of novel fluorescence-based and label-free noncanonical G4-quadruplex-like DNA biosensor for facile, specific, and ultrasensitive detection of fipronil. J. Hazard. Mater. 2021, 127939. [CrossRef] [PubMed]

46. Sun, L.; Zhao, Q. Direct fluorescence anisotropy approach for aflatoxin B1 detection and affinity binding study by using single tetramethylrhodamine labeled aptamer. Talanta 2018, 189, 442-450. [CrossRef]

47. Yilmaz, I.; Kaya, E.; Sinirlioglu, Z.A.; Bayram, R.; Surmen, M.G.; Colakoglu, S. Clinical importance of toxin concentration in Amanita verna mushroom. Toxicon: Off. J. Int. Soc. Toxinol. 2014, 87, 68-75. [CrossRef]

48. McKnight, T.A.; McKnight, K.B.; Skeels, M.C. Amatoxin and phallotoxin concentration in amanita bisporigera spores. Mycologia 2010, 102, 763-765. [CrossRef]

49. Abuknesha, R.A.; Maragkou, A. A highly sensitive and specific enzyme immunoassay for detection of beta-amanitin in biological fluids. Anal. Bioanal. Chem. 2004, 379, 853-860. [CrossRef]

50. He, K.; Zhang, X.; Zhao, R.; Wang, L.; Feng, T.; Wei, D.J.M.A. An enzyme-linked immunosorbent assay and a gold-nanoparticle based immunochromatographic test for amatoxins using recombinant antibody. Microchim. Acta 2016, 183, 2211-2219. [CrossRef]

51. Li, J.; Jing, L.; Song, Y.; Zhang, J.; Chen, Q.; Wang, B.; Xia, X.; Han, Q. Rapid Detection of Rongalite via a Sandwich Lateral Flow Strip Assay Using a Pair of Aptamers. Nanoscale Res. Lett. 2018, 13, 296. [CrossRef] [PubMed]

52. Soheili, V.; Taghdisi, S.M.; Hassanzadeh Khayyat, M.; Fazly Bazzaz, B.S.; Ramezani, M.; Abnous, K.J.M.A. Colorimetric and ratiometric aggregation assay for streptomycin using gold nanoparticles and a new and highly specific aptamer. Microchimica Acta 2016, 183, 1687-1697. [CrossRef]

53. Qiao, L.; Wang, H.; He, J.; Yang, S.; Chen, A. Truncated affinity-improved aptamers for $17 \beta$-estradiol determination by AuNPsbased colorimetric aptasensor. Food Chem. 2021, 340, 128181. [CrossRef] [PubMed]

54. Liu, X.; Lu, Q.; Chen, S.; Wang, F.; Hou, J.; Xu, Z.; Meng, C.; Hu, T.; Hou, Y. Selection and Identification of Novel Aptamers Specific for Clenbuterol Based on ssDNA Library Immobilized SELEX and Gold Nanoparticles Biosensor. Mol. (Basel Switz.) 2018, 23, 2337. [CrossRef] [PubMed]

55. Fischer, E. Einfluss der Configuration auf die Wirkung der Enzyme. Berichte der Deutschen Chemischen Gesellschaft. 1894, 27, 2985-2993. [CrossRef]

56. Morris, G.M.; Lim-Wilby, M. Molecular docking. Mol. Modeling Proteins 2008, 443, 365-382. 